\title{
Psychological and Functional Effects in Mastectomized Patients Treated With Virtual Reality
}

\author{
Macarena Aguirre-Carvajal* and Paula Marchant - Pérez \\ Faculty of Medicine, University of Valparaíso, Chile
}

Submission: January 29, 2018; Published: February 13, 2018

"Correspondence Address: Macarena Aguirre-Carvajal, Escuela de Kinesiología, Facultad de Medicina, Universidad de Valparaíso, Angamos no 655, piso 12, Reñaca, Viña del Mar, Chile, South America, Tel: +56 32 2603063/ +56 9 97483579; Email: macarena.aguirre.kine@gmail.com

Abstract

Objective: To describe the effect of early physical therapy with virtual reality on function of upper limb and risk of depression and anxiety in mastectomized patients.

Method: Descriptive study executed in women with unilateral mastectomy without shoulder pathologies, n=77 (41 study, 36 control), grouped by type of mastectomy: partial with sentinel lymph node (PMSL), partial with axillary dissection (PMAD) and modified radical mastectomy (MRM). At 7th day post surgery was applied a protocol of physical therapy with virtual reality exercises (Wii ${ }^{\mathrm{TM}}$ console). Patients were evaluated grade of upper limb ipsilateral function of mastectomy (Quick DASH) and for the risk of depression and anxiety (HADS). Measurements was before surgery (preoperative-day 0 ) and day $n^{\circ} 7$ and $n^{\circ} 30$ post surgery, period during which the protocol was applied in the study group. Statistical analysis is descriptive and the results are presented with averages and standard error (sd).

Results: Mastectomized patients who make early physical rehabilitation with virtual reality ( $\mathrm{Wii}^{\mathrm{TM}}$ console) increases upper limb ipsilateral function, especially MRM group, and by the other hand, decreases the risk of depression and anxiety unlike control group who maintains the risk.

Conclusion: Mastectomized patients who make early physical rehabilitation with virtual reality increase the functionality of the ipsilateral upper extremity after mastectomy and reduce the risk of depression and anxiety.

Keywords: Mastectomy; Virtual reality; Physical rehabilitation; Upper limb function; Depression; Anxiety

Abbreviations: PMSL: Partial Mastectomy with Sentinel Lymph Node; PMAD: Partial mastectomy with Axillary Dissection; MRM: Modified Radical Mastectomy; VR: Virtual Reality; HADS: Hospital Anxiety and Depression Scale; SG: Study Group; CG: Control Group; Sd: Standard Error

\section{Introduction}

The epidemiological profile is changing and life expectancy since birth increases; this had caused more chronic pathologies like cancer, being a public health trouble very important in morbidity and mortality terms. In 2008, the breast cancer ranked second in Chile like death cause in women, with a rate of 14.5/100000 habitants, that progressively increases from age 45 , reaching rates of $100 / 100000$ habitants for potentials years of life lost. The rates in region of Valparaíso showed that is the second with more morbidity risk for breast cancer [1].

Medical treatment for the breast cancer is varied, being the principal the breast surgery or mastectomy. Surgical techniques used, according the stage of cancer, are modified radical mastectomy (MRM), partial mastectomy with axillary dissection (PMAD) and partial mastectomy with sentinel lymph node (PMSL). Due to surgery, they are described immediately complications like acute pain, seroma, wound dehiscence, contractures and atrophy of the pectoralis major muscle, and the other hand, in the postoperative late, the complications are scar retraction, chronic pain, adhesions in the chest wall, paresthesia in the axillary area and internal side of the arm, lymphedema, loss of strength, postural alteration and shoulder mobility limited, and the last one is the sequel that generates more disability [2-4].

Shoulder mobility improves a bit over time, but the limitation can persist during weeks, months and even years, quickly installing rigidity and muscle atrophy after the surgery [5]. Women with cancer must deal, among other things, with the impact of the diagnosis and the side effects of the treatment, fear of recurrence of cancer, decrease in their health and increase of disability levels in addition to lack of functionality in the upper limb, they experience psychological stress that affects their quality of life $[6,7]$ like depression and anxiety. When the psychological effects are presents together with cancer, decrease the adherence to the treatment, hospitals stays are prolonged and survival opportunities are reduced [8].

To reduces the physicals and psychological complications, exercises are used widely recognizes like a tool very important to recovery and rehab women post mastectomy and, according 


\section{Cancer Therapy \& Oncology International Journal}

to reviews and Meta-analyses, suggests that exercises decrease physical and psychological discomfort rates after cancer treatment [9]. The evidence support that affectivity of exercises programs to reduces symptoms and improve the quality of life after cancer diagnosis. Silva [10] supports the theory that patients with breast cancer should be included in post-surgery rehab programs due real benefits in improve de quality of life. Results suggest that interventions with physical activities during and after treatment can to prevent weakening and improve cardio respiratory performance, physical health, immunity responses, strong and flexibility, corporal image, self-esteem, frame of mind and stimulates treatment adherence. Also, the exercises are associated with less hospitalizations days, number and severity of side effects, including nausea, fatigue and pain [11].

Virtual reality (VR) is a science based on computer use and other dispositive, whose purpose is produce simulation that permits have the sensation of be there, in the environment simulated [12]. In games with VR, people executes movements and gestures through sports simulated that are generate by these systems, generating benefits in several types of therapies, both in young people and in the elderly, what has attracted attention in the health teams around the world. Schneider [13] studied the use of VR in elderly women with chemotherapy treatment for breast cancer and he evidenced a decrease in fatigue and he indicated that is an easy alternative to implement, generating a good adherence to the treatment.

In this context, a more dispositive due to the ease of use and low purchase price and easiness to use in patients of all age and health teams is the Nintendo Wii ${ }^{\mathrm{TM}}$, which is successful in rehabilitation to improve the motivation of the patients in their therapies, with a design that can generate movements of the all body [14]. Saposnik [15] in his studies with VR concludes that these games are an alternative to do safe exercises, viable an effective potentially to expedite of the rehabilitation process and to promote the motor recovery. In relation to the time of exercise with VR there is no consensus but several authors' uses exercises during 30 minutes per session in their investigations $[16,17]$.

Considering the excellent experience of a lot of health teams around the world in the use of VR in patients with cancer is that the opportunity to carry out this study that aims to describe if in mastectomized patients the early physical rehabilitation with VR in upper limb allows to maintain and recovery the joint mobility and their surrounding tissue, stimulating the recovery the function of the upper limb ipsilateral and decrease the depression and anxiety risk.

\section{Materials and Methods}

This is a descriptive study that includes unilateral mastectomized patients from Carlos Van Bûren Hospital of Valparaiso in Chile, during year 2013 and 2014. Who accepted take part of this study had to sign the consent of participation and they had must be over 18 years old. Patients with previous shoulder pathologies in the ipsilateral shoulder of the mastectomy, previous breast surgery, previous radiotherapy and who can' it follow instructions were excluded. The subjects was divided in two group, study group (SG) with VR intervention $(n=41)$ and control group (CG) without VR intervention $(n=36)$, additionally, each group was divided accord mastectomy type: PMSL, PMAD and MRM.

The function of the upper limb ipsilateral of the mastectomy was evaluated with Quick DASH test, the dysfunction is valued from 0 to 100 points and a higher score indicates greater disability [18]. To evaluate the risk of depression and anxiety, the Hospital Anxiety and Depression Scale (HADS) was used, which assessed the risk of presenting these psychological troubles [19]. It's a self-applied questionnaire with seven questions in the depression item and seven questions in the anxiety item. The intensity or frequency of the symptoms is evaluated with Likert scale of 4 point (range of 0-3) and the final score is a directly proportional, that is, a higher score means more risk of depression and anxiety.

The measures with the described tools were made before the surgery (pre-operatory, day 0 ) and post-surgery at the $7^{\text {th }}$ day and the $30^{\text {th }}$ day. The physical rehabilitation protocol with VR exercises (Nintendo $\mathrm{Wii}^{\mathrm{TM}}$ console) was applied in the SG. It was 10 sessions of 32 minutes: three serial of 10 minutes of effective exercise and two serial of 1 minute to rest, three days per week, between $7^{\text {th }}$ day and $30^{\text {th }}$ day post-surgery. Therapeutic sequences with the games are in the Table 1 . The analysis statistical was made with MiniTab $\AA 14$ program and descriptive statistical was used to analyzed the results, they are presents with standard error (sd).

Table 1: Therapeutic sequence used in the early rehabilitation protocol with virtual reality.

\begin{tabular}{|c|c|c|}
\hline Session & $\begin{array}{l}\text { Nintendo } \mathrm{Wii}^{\mathrm{TM}} \\
\text { Game }\end{array}$ & Patient's Posture \\
\hline $1 \& 2$ & $\begin{array}{l}\text { Air Sport, Piloting - } \\
\text { Tourism mode }\end{array}$ & $\begin{array}{l}\text { Seated, Wii remote in ipsilateral } \\
\text { hand, shoulder in } 90^{\circ} \text { of flexion, } \\
\text { elbow extended. }\end{array}$ \\
\hline $3 \& 4$ & $\begin{array}{l}\text { Wakeboarding, } \\
\text { Beginner mode }\end{array}$ & $\begin{array}{c}\text { Seated, Wii remote in both hands, } \\
\text { shoulders in flexion, elbows } \\
\text { extended. }\end{array}$ \\
\hline $5 \& 6$ & $\begin{array}{l}\text { Swordplay, Speed } \\
\text { slice mode }\end{array}$ & $\begin{array}{l}\text { Bipedal, Wii remote in ipsilateral } \\
\text { hand, slight flexion of shoulder } \\
\text { and elbow }\end{array}$ \\
\hline $7 \& 8$ & $\begin{array}{c}\text { Frisbee } \AA \text {, Frisbee } \AA \\
\text { Dog mode }\end{array}$ & $\begin{array}{c}\text { Bipedal, Wii remote in ipsilateral } \\
\text { hand, adduction - abduction of } \\
\text { shoulder, slight flexion of elbow. }\end{array}$ \\
\hline $9 \& 10$ & $\begin{array}{l}\text { Archery, Beginner } \\
\text { mode }\end{array}$ & $\begin{array}{l}\text { Bipedal, hold Wii remote in } \\
\text { ipsilateral hand with } 90^{\circ} \text { shoulder } \\
\text { flexion and extended elbow, } \\
\text { opposite hand performs the throw. }\end{array}$ \\
\hline
\end{tabular}

\section{Results}

The age of the patients who participated was between 26 and 83 years old, mean of $58.76 \pm$ sd 1.46 years old. In SG the age was $57.66 \pm$ sd 1.65 years old and in the CG was $60.03 \pm$ sd 2.51 


\section{Cancer Therapy \& Oncology International Journal}

years old. Accord the surgery type, in the SG, 39.02\% was in the PMSL group, $41.46 \%$ was in the PMAD group and $19.52 \%$ was in the MRM group. In the CG, $44.44 \%$ was in the PMSL group, $36.11 \%$ was in the PMAD group and $19.45 \%$ was in the MRM group. All results of measurements are with SD. Accord the function of the shoulder showed by the patients of SG, at the day 0 , the mean was $10.94 \pm 3.87$ for PMSL, $5.61 \pm 1.55$ for PMAD and $16.11 \pm 5.46$ for MRM. At 7 th day, the mean showed was $27.69 \pm 5.25$ for PMSL, $30.89 \pm 4.47$ for PMAD y $23 \pm 7$ for MRM.
And at 30th day the mean was $12.99 \pm 2.67$ for PMSL, $12.01 \pm 2.86$ for PMAD and $17.86 \pm 6.30$ for MRM (Figure 1). In the patients of CG, the mean was $8.24 \pm 2.33$ for PMSL, $5.08 \pm 1.31$ for PMAD and $11.60 \pm 4.83$ for MRM. At 7 th day, the functionality mean was $21.25 \pm 4.76$ for PMSL, $22.59 \pm 5.88$ for PMAD and $28.59 \pm 8.01$ for MRM. In the evaluation at 30th day, the mean was $15.06 \pm 3.55$ for PMSL, $15.24 \pm 6$ for PMAD and $20.13 \pm 5.79$ for MRM (Figure $1)$. The results of risk of depression and anxiety are in the Tables $2 \& 3$.
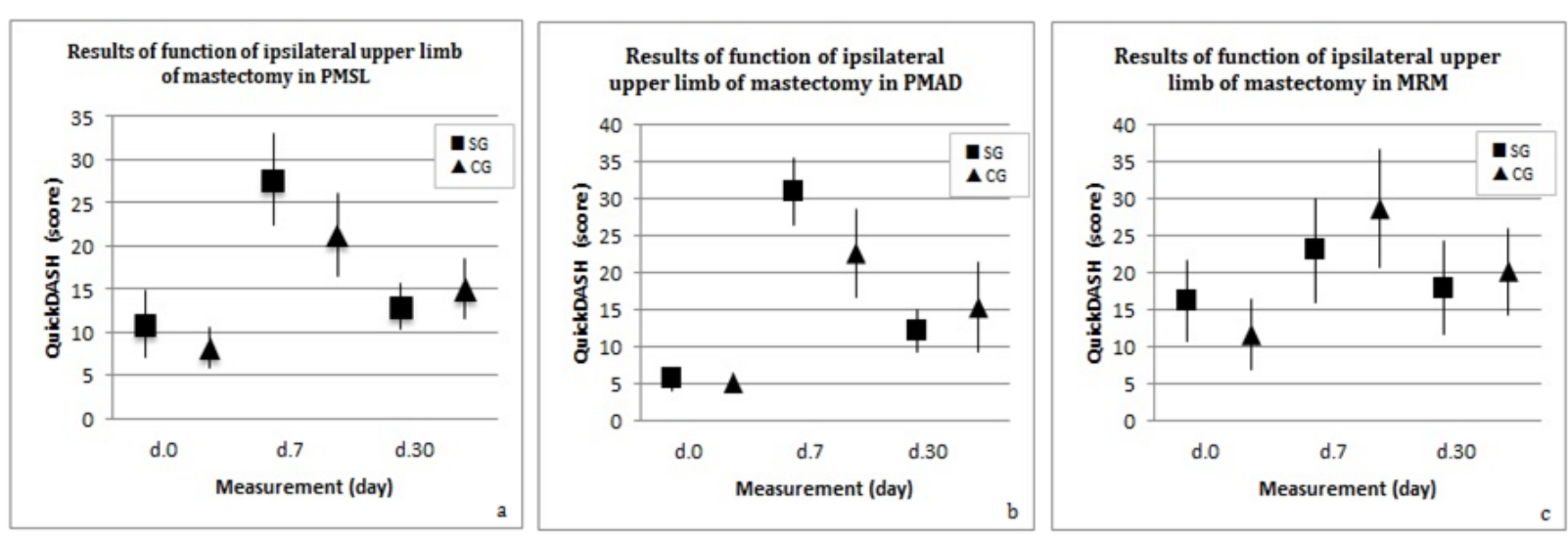

Figure 1: The Quick DASH test evaluated the function of the upper limb ipsilateral of the mastectomy at day 0 (d.0), at the 7th day (d.7) and the 30th day (d.30). The graphs show the means obtained in PMSL (a), PMAD (b) and MRM (c) of SG and CG. SG: study group; CG: control group; PMSL: partial mastectomy with sentinel node group; PMAD: partial mastectomy with axillary dissection group; MRM: modified radical mastectomy group.

Table 2: Results of risk of depression of HADS.

\begin{tabular}{|c|c|c|c|c|c|c|}
\hline & \multicolumn{2}{|c|}{ PMSL } & \multicolumn{2}{c|}{ PMAD } & \multicolumn{2}{c|}{ MRM } \\
\hline & SG & CG & SG & CG & SG & CG \\
\hline d.0 & $\begin{array}{c}4,69 \pm \\
0,88\end{array}$ & $\begin{array}{c}3,19 \pm \\
0,77\end{array}$ & $\begin{array}{c}4,00 \pm \\
1,11\end{array}$ & $\begin{array}{c}3,31 \pm \\
1,04\end{array}$ & $\begin{array}{c}3,38 \pm \\
1,66\end{array}$ & $\begin{array}{c}3,43 \pm \\
1,40\end{array}$ \\
\hline d.7 & $\begin{array}{c}3,81 \pm \\
0,88\end{array}$ & $\begin{array}{c}2,81 \pm \\
0,68\end{array}$ & $\begin{array}{c}4,29 \pm \\
0,95\end{array}$ & $\begin{array}{c}3,54 \pm \\
1,04\end{array}$ & $\begin{array}{c}4,00 \pm \\
1,80\end{array}$ & $\begin{array}{c}3,43 \pm \\
1,17\end{array}$ \\
\hline d.30 & $2,56 \pm$ & $2,50 \pm$ & $\begin{array}{c}4,00 \pm \\
1,06\end{array}$ & $\begin{array}{c}3,54 \pm \\
1,29\end{array}$ & $\begin{array}{c}2,50 \pm \\
1,04\end{array}$ & $\begin{array}{c}4,29 \pm \\
2,53\end{array}$ \\
\hline
\end{tabular}

d.0: Pre-operatory, day 0; d.7: 7th day post-surgery; d.30: 30th day post-surgery; PMSL: partial mastectomy with sentinel node group; PMAD: partial mastectomy with axillary dissection group; MRM: modified radical mastectomy group; SG: study group; CG: control group

Table 3: Results of risk of anxiety of HADS.

\begin{tabular}{|c|c|c|c|c|c|c|}
\hline & PMSL & & PMAD & & MRM & \\
\hline & SG & CG & SG & CG & SG & CG \\
\hline d.0 & $\begin{array}{c}7,94 \pm \\
1,26\end{array}$ & $\begin{array}{c}5,88 \pm \\
0,92\end{array}$ & $\begin{array}{c}5,35 \pm \\
0,84\end{array}$ & $\begin{array}{c}6,85 \pm \\
1,03\end{array}$ & $\begin{array}{c}7,75 \pm \\
2,14\end{array}$ & $\begin{array}{c}5,43 \pm \\
1,31\end{array}$ \\
\hline \multirow{2}{*}{ d. 7} & $\begin{array}{c}5,94 \pm \\
\end{array}$ & $\begin{array}{c}4,94 \pm \\
\text { d. }\end{array}$ & $\begin{array}{c}6,00 \pm \\
1,12\end{array}$ & $\begin{array}{c}5,62 \pm \\
1,04\end{array}$ & $\begin{array}{c}6,25 \pm \\
2,27\end{array}$ & $\begin{array}{c}3,86 \pm \\
1,20\end{array}$ \\
\hline \multirow{2}{*}{ d.30 } & $5,38 \pm$ & $4,06 \pm$ & $4,88 \pm$ & $5,62 \pm$ & $5,25 \pm$ & $4,29 \pm$ \\
& 0,90 & 0,84 & 1,11 & 1,49 & 1,79 & 1,92 \\
\hline
\end{tabular}

d.0: Pre-operatory, day 0; d.7: 7th day post-surgery; d.30: 30th day post-surgery; PMSL: partial mastectomy with sentinel node group; PMAD: partial mastectomy with axillary dissection group; MRM: modified radical mastectomy group; SG: study group; CG: control group.

\section{Discussion}

In this research observed that if applicate and exercises protocol with VR in the ipsilateral upper limb of the mastectomy, from seventh day after surgery, no matter type of mastectomy, it favors recovery the functionality of shoulder and decreases the risk of depression and anxiety. When evaluating the function of the upper extremity after surgery, at 7th day, SG and CG showed decrease in the movement of the ipsilateral upper limb of the mastectomy in all subgroups (PMSL, PMAD and MRM). This limitation is because there is a trauma by the surgery and our results are accord like LeBlanc's results [18].

The function of ipsilateral upper limb to the mastectomy evaluated after exercise protocol application evidenced an increase that is similar to the results of Petito [20] \& Rett [21], demonstrating the positive that is in the patients made physical therapy to favor to the incorporation in the daily activities and to get better their quality of life. Therefore, perform exercises of rehabilitation in the ipsilateral upper limb after mastectomy is very important to minimize the post-surgery complications. In the case of this study, all groups increased the functionality of upper limb but the increase more significant was in the PMAD of SG. In the case of CG, the functionality increased in smaller amount. The difference in both groups is because the patients 
with early exercises intervention they do not install side effects of surgery, like said Hechavarría [5].

In relation to the risk on anxiety in women with breast cancer, other studies show that the women react with anxiety in several phases [19]. Immediately, after breast cancer diagnosis, women present high levels of anxiety but before and after surgery they present symptoms and state of median anxiety [22]. The above is coincident with the results obtained in this study in both groups. The women evaluated the day before surgery presented median levels of anxiety, exception PMSL in CG. At 7th day, the anxiety levels decreases and at 30th day, in SG the levels of anxiety and depression decreases, demonstrating that the exercises help to lower the psychological symptoms in women with mastectomy. The principal limitation of this study was the difficult to adherence of the patients from distant areas so that is the challenge to the next investigations.

\section{Conclusion}

The protocol of exercises with VR in ipsilateral upper limb to the mastectomy, since 7th day post-surgery no matter type of surgery, showed be efficient in improve the function of upper limb and decrease the risk of depression and anxiety.

\section{Acknowledgement}

Corporación Nacional del Cáncer, filial Valparaíso. Policlínico de Patología Mamaria HCVB. Fondo Nacional de Investigación en Salud, CONICYT.

\section{Conflict of Interest}

There is no conflict of interest in this study.

\section{References}

1. Ministerio de Salud (2011) Guía Clínica Cáncer De Mama, Santiago: Minsal, Chile, USA.

2. Del Val Gil JM, López Bañeres MF, Rebollo López FJ, Utrillas Martínez AC, Minguillón Serrano A (2001) Cáncer de mama y mastectomía. Estado actual. Cir Esp 69: 56-64.

3. Box RC, Reul-Hirche HM, Bullock-Saxton JE, Furnival CM (2002) Shoulder movement after breast cancer surgery: results of a randomised controlled study of postoperative physiotherapy. Breast Cancer Res Treat 75(1): 35-50.

4. Toro F, Villalón I, Olmedo C, Ruit F, Moraga C, et al. (2009) Tratamiento Quirúrgico de la inestabilidad de hombro. Evaluación de resultados. Rev Chilena Ortop y Traum 50: 193-200.

5. Hechavarria Z, Hernández M, Maturell J (2013) Fisioterapia en mastectomizadas con alteraciones físicas y funcionales en el hombro ipsilateral. Medisan 17(10): 6080-6087.

6. Vivar C (2012) Impacto psicosocial del cáncer de mama en la etapa de larga supervivencia: propuesta de un plan de cuidados integral para supervivientes. Rev Aten Primaria 44(5): 288-292.

7. Reich M, Remor E (2010) Variables Psicosociales asociadas con calidad de vida relacionada con la salud en mujeres con cáncer de mama postcirugía: una revisión sistémica. Cienc Psicol 4(2): 179-223.
8. Robles R, Morales M, Margarita L, Morales J (2009) Depresión y Ansiedad en Mujeres con Cáncer de Mama: El papel de la afectividad y el soporte social. Psicooncología 6(1): 191-201.

9. Spence RR, Heesch KC, Brown WJ (2010) Exercise and cancer rehabilitation: A systematic review. Cancer Treat Rev 36(2): 185-194.

10. Pinto e Silva MP, Sarian LO, Morais SS, Pace do Amaral MT, Freire de Oliveira MM, et al. (2008) Implications of a Postoperative Rehabilitation Program on Quality of Life in Women with Primary Breast Cancer treated with Sentinel Lymph Node Biopsy or Complete Axillary Lymph Node Dissection. Ann Surg Oncol 15(12): 3342-3349.

11. Hayes S, Rye S, Battistutta D, Yates P, Pyke C, et al. (2011) Design and implementation of the Exercise for Health trial-A pragmatic exercise intervention for women with breast cancer. Contemporary Clinical Trials 32: 577-585.

12. Ji-Hyuk Park, Sang-Heon Lee, Dae-Sik Ko (2013) The Effects of the Nintendo Wii Exercise Program on Chronic Work-related Low Back Pain in Industrial Workers. J Phys Ther Sci 25(8): 985-988.

13. Schneider SM, Prince-Paul M, Allen MJ, Silverman P, Talaba D (2004) Virtual Reality as a Distraction Intervention for Women Receiving Chemotherapy. Oncol Nurs Forum 31(1): 81-88.

14. Anderson F, Annett M, Bischof WF (2010) Lean on Wii: Physical Rehabilitation with Virtual Reality and Wii Peripherals". Stud Health Technol Inform 154: 229-234.

15. Saposnik G, Teasell R, Mamdani M, Hall J, Mcllroy W, et al. (2010) Effectiveness of Virtual Reality Using Wii Gaming Technology in Stroke Rehabilitation: A Pilot Randomized Clinical Trial and Proof of Principle. Stroke 41(7): 1477-1484.

16. Kho ME, Damluji A, Zanni JM, Needham DM (2012) Feasibility and observed safety of interactive video games for physical rehabilitation in the intensive care unit: a case series. J Crit Care 27(2): 219.e1-219. e6.

17. Yong Joo L, Soon Yin T, Xu D, Thia E, Pei Fen C, et al. (2010) A feasibility study using interactive commercial off-the-shelf computer gaming in upper limb rehabilitation in patients after stroke. J Rehabil Med 42(5): 437-441.

18. Le Blanc M, Stineman M, De Michele A, Stricker C, Mao JJ, et al. (2014) Validation of Quick DASH Outcome Measure in Breast Cancer Survivors for upper extremity disability. Arch Phys Med Rehabil 95(3): 493-498.

19. Stafford L, Judd F, Gibson P, Komiti A, Quinn M, et al. (2014) Comparison of the Hospital Anxiety and Depression Scale and the Center for Epidemiological Studies Depression Scale for detecting depression in women with breast or gynecologic cancer. Gen Hosp Psychiatry 36(1): 74-80.

20. Petito EL, Nazário ACP, Martinelli SE, Facina G, Gutiérrez MGR, et al. (2012) Application of a domicile-based exercise program for shoulder rehabilitation after breast cancer surgery. Rev Latino-Am Enfermagem 20(1): 35-43.

21. Rett MT, Mesquita PJ, Carvalho A, Pereira D, Melo De Santana J, et al. (2012) A cinesioterapia reduz a dor no membro superior de mulheres submetidas à mastectomia ou quadrantectomia. Rev Dor São Paulo 13(3): 201-207.

22. Caniçali C, Nunes L, Pires P, Costa F, Costa M (2012) Ansiedad en mujeres con cáncer de mama. Enfermería Global 11(28): 52-62. 


\section{Cancer Therapy \& Oncology International Journal}

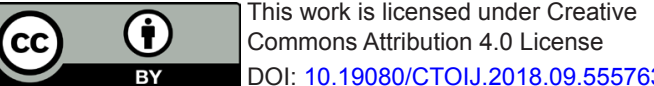

Your next submission with Juniper Publishers will reach you the below assets

- Quality Editorial service

- Swift Peer Review

- Reprints availability

- E-prints Service

- Manuscript Podcast for convenient understanding

- Global attainment for your research

- Manuscript accessibility in different formats

( Pdf, E-pub, Full Text, Audio)

- Unceasing customer service

Track the below URL for one-step submission https://juniperpublishers.com/online-submission.php 